\title{
Cost Effective Cloud based Business Intelligence Model for Small Scale Organizations
}

\author{
Kanwalpreet Kaur \\ Student(M.Tech) \\ Punjab Technical \\ University,Punjab
}

\author{
Neha Azad \\ Student(M.Tech) \\ Punjab Technical \\ University,Punjab
}

\author{
Prabhdeep Singh \\ Asssistant Professor \\ Punjab Technical \\ University,Punjab
}

\begin{abstract}
Business Intelligence (BI) is the ability for an organization to collect, maintain, and organize data and information to provide historical, current and predictive views of operations. Cloud Computing concepts promise new options for an internet based resourcing of hardware and software. Cloud BI Portal will provide a utility model of computing with lower entry and maintenance cost and multiple delivery models. It will result in better adoption of BI systems mainly in case of small scale organizations where cost factor is a major concern. The target market for Cloud-BI software is currently small scale companies or organizations with few IT resources, limited budget to spend on servers and software, and minimal to no BI expertise .BI Cloud portal can be accessed from anywhere through internet, thus providing BI services to the organization more efficiently. This contribution provides a solution to the BI related problems being faced by small scale organizations like an institute, by designing a model for the BI Cloud Portal which will provide all BI facilities within the economic boundaries.
\end{abstract}

\section{General Terms}

Business Intelligence (BI), Cloud Computing, BI Strategy

\section{Keywords}

BI Portal, Institute Management System, Cloud BI Strategy

\section{INTRODUCTION}

Zeng et al. (2006) define BI as "The process of collection, treatment and diffusion of information that has an objective, the reduction of uncertainty in the making of all strategic decisions." BI provides integration. It is also reflected in DWH (Data Warehousing) which is core of BI Approach and provides a subject-oriented, non-volatile and integrated data repository for a variety of analysis and reporting applications [1]. But in traditional BI the integration is achieved at the cost of increased complexity and management capacity. The infrastructure also sometimes limits the exploitation of BI, as it does not match timely enough to changing business requirements (TDWI 2008)[3].

Due to these difficulties of Traditional BI systems, Cloud Computing is becoming more appealing. BI cloud portal can provide BI services which can be accessed by users simply through a Web browser via internet from anywhere in the world .The reports and applications can be packaged (i.e., Software-as-a-Service or SaaS) or custom-built by the service provider or customer using Platform-as-a-Service (PaaS) or other tools[4],[5].
This paper takes a differentiated look at the subject of BI and Cloud Computing in order to provide Cloud BI Services to small scale organizations by designing a Cloud BI portal for a small organization like an Institute which help in managing student data and organization data through Cloud BI Services by generating reports (SaaS) and saving data in servers of Cloud Provider (IaaS) rather than own server of Institute. By this there will be no hardware and software to buy, install, tune, and upgrade. Institute will pay for the services to the Cloud Provider in Pay-as -you-go manner. In this manner Cloud will speed delivery and drive down the cost [6][8].

Table 1. Comparision Of Traditional BI And Cloud BI Services

\begin{tabular}{|c|c|c|}
\hline & Traditional BI & Cloud BI \\
\hline $\begin{array}{c}\text { Key } \\
\text { Charac } \\
\text { terstics }\end{array}$ & $\begin{array}{ll}\text { - } & \text { High } \\
\text { infrastructure } \\
\text { requirements } \\
\text { - } \quad \text { Unpredictable } \\
\text { load } \\
\text { - } \quad \text { High upfront } \\
\text { investment } \\
\text { - } \quad \text { High } \\
\text { development } \\
\text { \& } \\
\text { maintenance } \\
\text { costs } \\
\text { Dependency } \\
\text { on IT }\end{array}$ & 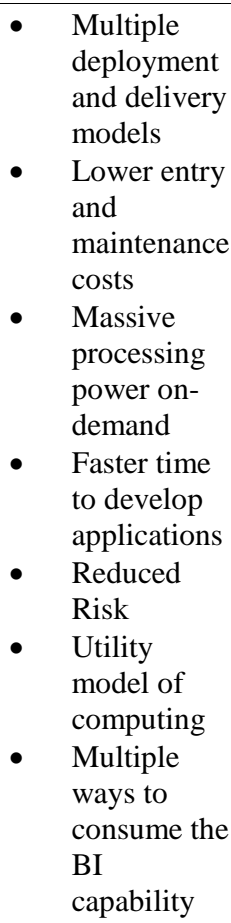 \\
\hline Issues & $\begin{array}{ll}\text { - } & \text { a Limited } \\
\text { - } & \text { adoption } \\
\text { Longer cycle } \\
\text { time for BI } \\
\text { application } \\
\text { - } & \text { Restricted } \\
& \text { Availability }\end{array}$ & $\begin{array}{ll}- & \text { Security } \\
\text { - } & \text { No } \\
& \text { flexibility in } \\
& \text { design } \\
\text { - } & \text { No } \\
& \text { flexibility in } \\
\text { choosing } \\
\text { vendors for } \\
\text { specific }\end{array}$ \\
\hline
\end{tabular}




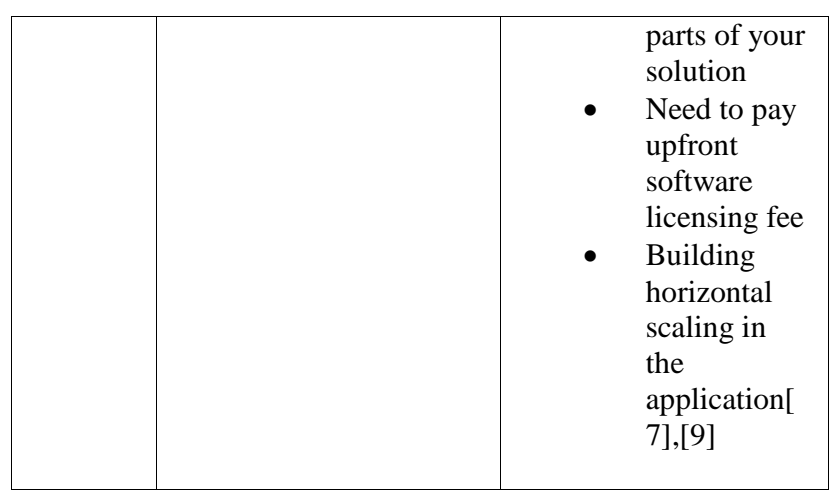

\section{BENEFITS AND RISKS}

The Cloud offers numerous benefits for organizations that want to run reports and dashboards within economic constraints. Organization using Cloud BI does not have to hire IT people, pay and manage. Applications upgrade automatically and can be scaled seamlessly. Customers pay a monthly subscription based on usage rather than an upfront licensing fee. Essentially, the Cloud speeds delivery and drives down costs enhancing the portability, extendibility, flexibility and scalability. But there are concerns. One of the biggest risk to Cloud BI today is security, or at least the perception that data in the Cloud is less secure than data housed in a corporate data center. In reality, data is actually safer in the Cloud than in many corporate data centers. The real issue is not security, it's "control." Executives today simply feel safer if their data is housed in a corporate data center. To be fair, some companies, especially those in financial services, must comply with regulations that currently require them to keep data on premise. Data Integration, Data Migration and Performance Optimizations are also big concern [2],[16],[17].

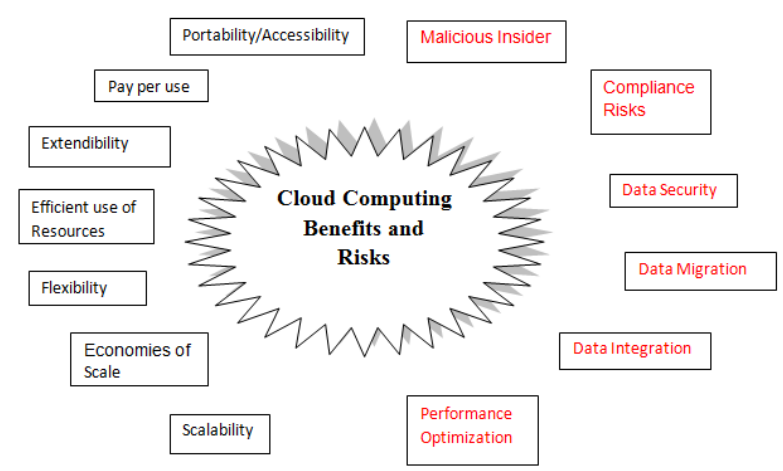

Fig 1: Benefits and Risks of Cloud Computing in BI

\section{STAGES OF CLOUD BI}

Algorithm for Stages of Cloud BI integration.

3.1 Analyzing the Business Processes, Infrastructure and other Resources.

3.2 Designing the traditional solutions using Cloud Technology.

3.2.1 Mapping of Cloud Model and BI Strategy.

3.2.2 Evaluation of different Plans.

3.2.3 Identifying the Cloud BI Providers according to the Business Requirements.

\subsection{Selection of Cloud BI Provider.}

\subsection{Implementation of Cloud BI Strategy.}

3.5 Management of Cloud BI Solution[18].

\section{DECISION MODEL AND} IMPLEMENTATION

\subsection{Analyzing the Business Processes,} Infrastructure and other Resources.

It is mandatory to analyze the present stage of business processes and resources both at the internal and external perspective and to identify those aspects which can be performed by the cloud strategy. Thus Business objectives should be well understood with the cost-benefit analysis and other major aspects of the business.

\subsection{Designing the traditional solutions using Cloud Technology.}

This stage includes the Cloud BI solution Design with the use of mapping Cloud Computing Model with Business Intelligence Strategy. Analyzing and evaluating the various Cloud BI solutions from various vendors.

\subsubsection{Mapping of Cloud Model and BI Strategy.}

4.2.2 Evaluation of different Plans.

4.2.3 Identifying the Cloud BI Providers according to the Business Requirements

\subsection{Selection of Cloud BI Provider.}

In this stage evaluating and selecting the cloud BI solution is done according to the decision model. Decision model includes iterative strategy of choosing best solution which eliminates unacceptable configuration or solution in each iteration. Decision Model stages include:

4.3.1 Services Analysis check whether the BI Saas provider complies with the emerging Saas Standards and study the service-level agreements (SLAs) agreed upon by the vendor and keep track of actual application usage.

4.3.2 Cost-benefit Analysis based on the tangible assets architecture, monthly expenses and long-term total ownership costs based on the specific environment and requirements. 
4.3.3 Strategic Analysis includes a detailed cloud to onpremise migration strategy in place in case the Cloud Vendor fails to perform according to desired expectations.

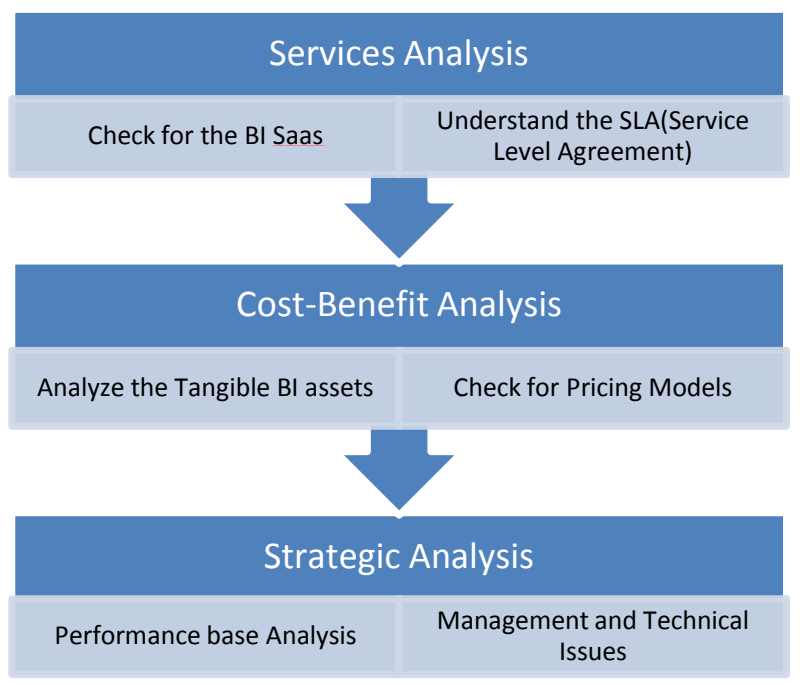

Fig 2: Decision Model for Choosing the Best Cloud BI Solution

\subsection{Implementation of Cloud BI Strategy}

Implementing BI strategy on cloud concentrates on the accurate migration of data, services and resources on the Cloud Platform. It includes iterative deployment of these functionalities on the Cloud with high concentration on the data accuracy, data management and security issues. With this, users at this end are highly sophisticated in dealing with these systems.

\subsection{Management of Cloud BI Solution}

After implementing the BI strategy on cloud environment it is mandatory for every organization to keep track of the services and resources being provided by the Cloud BI Solution. A management team is organized at the organization that fully works out how the software and services will be transferred and over what period of time.

\section{NEED FOR BI CLOUD PORTAL IN SMALL SCALE ORGANIZATIONS}

According to the recent survey of BI Leadership Forum which is a global network of BI Directors and other BI professionals , small companies are leading the way in the usage of Cloud BI. The target market for Cloud-BI software is currently small scale companies or organizations with few IT resources, limited budget to spend on servers and software, and minimal to no BI expertise. For small scale Cloud BI services are God send[14]

Source: BI Leadership Forum, June, 2011. Based on 112 responses.

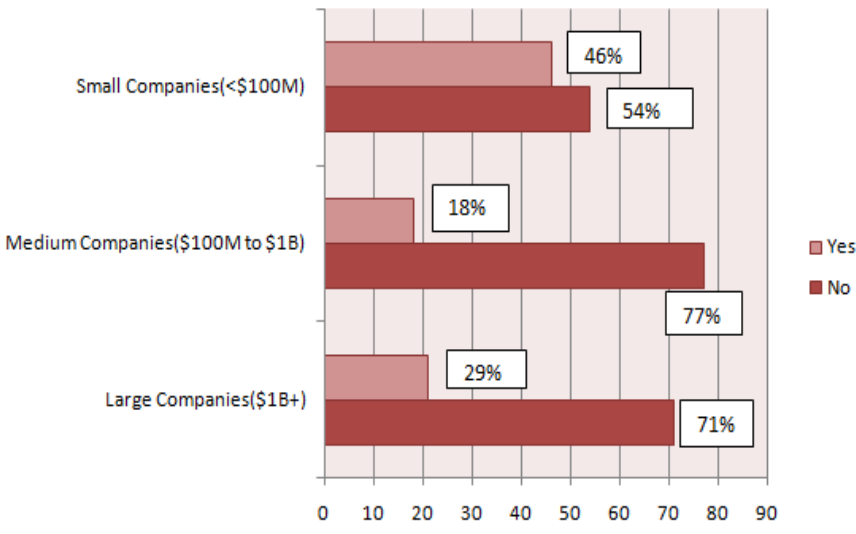

Fig 3: Cloud BI Deployment by Company Size

Are you using Cloud For any elements of your BI program?

\subsection{Conclusion from above survey:}

5.1.1 Almost half of small companies under $\$ 100 \mathrm{M}$ in annual revenues (46\%) use Cloud BI.

5.1.2 In contrast, large companies with over $\$ 1 \mathrm{~B}$ in annual revenues are almost less than half as likely to adopt the cloud $(29 \%)$.

5.1.3 Medium-sized companies with between \$100M and $\$ 1 \mathrm{~B}$ in annual revenues lag further behind with less than onefifth using BI in the Cloud (18\%).

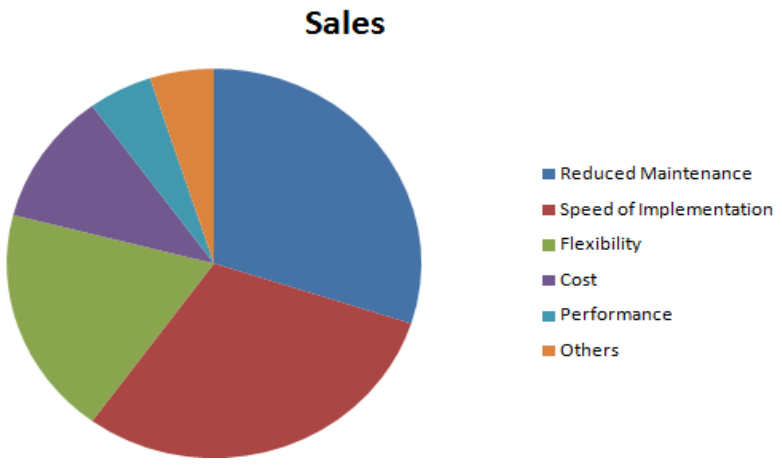

Fig 4: What is your Top Reason for using Cloud BI

\subsection{Conclusion from above survey:}

5.2.1 Organizations that adopted cloud to "Speed

of Deployment" (30\%)

5.2.2 "Reduced Maintenance" (30\%),

5.2.3 "Flexibility" (19\%)

5.2.4 "Cost" (11\%).

5.2.5 "Performance" and "Others" (5\% each)[10],[11]. 


\section{SOLUTION AND DESIGN OF CLOUD BI PORTAL FOR SMALL SCALE ORGANIZATION(INSTITUTE MANAGEMENT SYSTEM)}

This section will provide the solution to above problem and a design of Cloud BI Portal for a small organization like an institute will be presented:

\subsection{Design Of The Solution}

Institute Management System comprises of following users (members) which will be accessing BI Cloud Portal through internet after registering themselves on the Portal. Any New user can send registration request to Cloud BI Admin and become the member of the portal and can access the features:

6.1.1 Admin Dept. Head(Institute): It has the following information of the institute, which is to be stored at server of cloud.

6.1.1.1 Student Details: It comprises of details like Student Personal data, History of Earlier Academic Details, Current Record(Roll No, Marks, Sem ), Guide information of Each student, Project Information, Training Details.

\subsubsection{Academic Calendar}

\subsubsection{Detail of Departments.}

\subsubsection{Detail of Societies}

6.1.1.5 Faculty Details: It comprises details like Personal data, Faculty Profile, Faculty Recruitment Detail, Research Under Faculty, Timetable.

6.1.2 Timetable Co-ordinator: It maintains the information of class room availability, faculty availability, labs and others(Auditorium, Convention Hall etc.)

6.1.3 Finance Head: Student fee details, Faculty salary, Funds(Sponsors, Outside Aid),Expenditure details are maintained by finance head.

\subsubsection{TPO(Training Placement Officer): It} maintains Current Year Placement Details, History of Placement details, Industrial Training.

6.1.5 Library Head: Book Details present in the library are maintained.

6.1.6 Sports Co-ordinator: It maintains types of Sports, Current event Details and History of Sports events in the institute.

6.1.7 Faculty: Faculty can add and view student data and can generate reports.

Above of these users use Cloud BI Portal to add, enter and save the information of the institute in the servers provided by the Cloud Provider instead of using their own servers, thus reducing the infrastructure and maintenance cost. Moreover the users like Finance Head and Faculty use the features of BI tools provided by the Cloud BI Portal to generate reports regarding student's performance or regarding total expenditure done by institute. Thus Cloud BI portal provides overall package for maintaining, accessing and storing institute's data in an efficient manner, thus proving Cloud BI to be more efficient than Traditional BI.
Design of the solution is represented through Data Flow Diagrams, ER Diagram and UML Diagrams(Use Case Diagram,Sequence Diagram).

\subsection{Data Flow Diagrams}

DFD are the graphical representation of flow of data through an information system.

\subsubsection{Context Level DFD:}

It consists of three entities Cloud BI Administrator, New User(want to register) and Member(registered user).

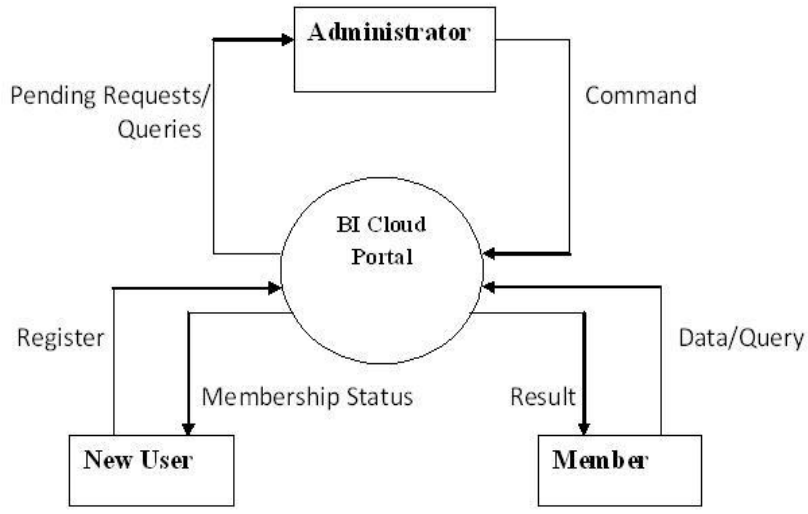

Fig 5: Context Level DFD

\subsubsection{Level-1 DFD for New User:}

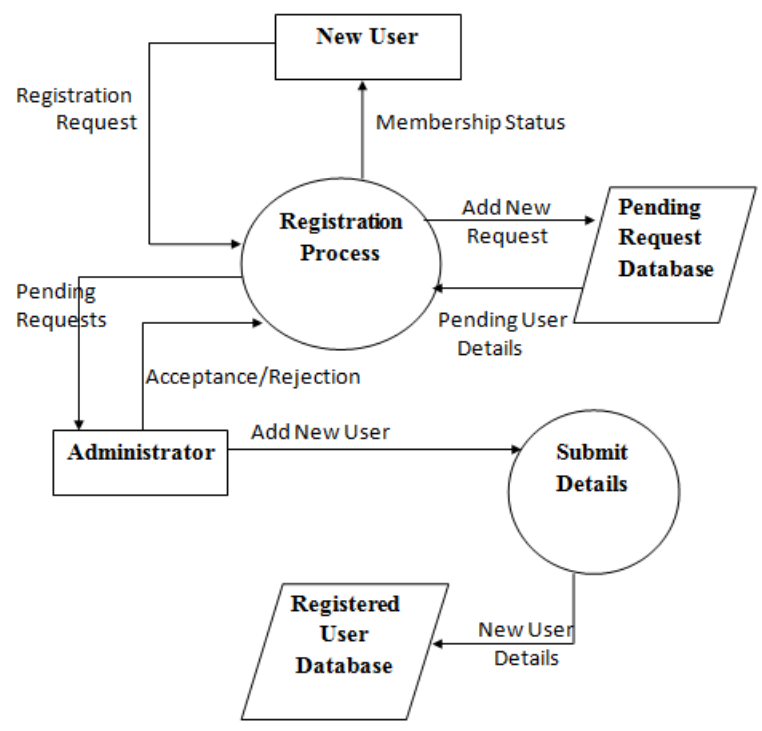

Fig 6: Level-1 DFD for New User 


\subsubsection{Level-1 DFD for Member:}

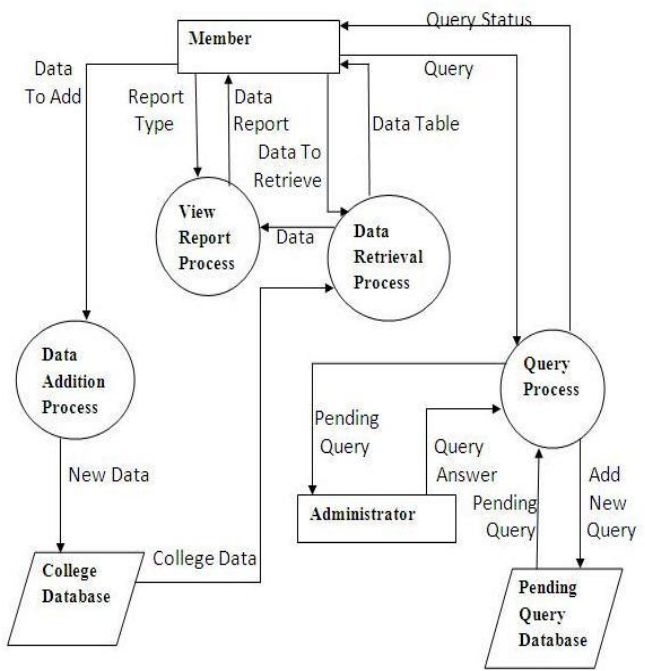

Fig 7: Level-1 DFD for Member

\subsection{E-R Diagram:}

It illustrates the relationship between different entities.

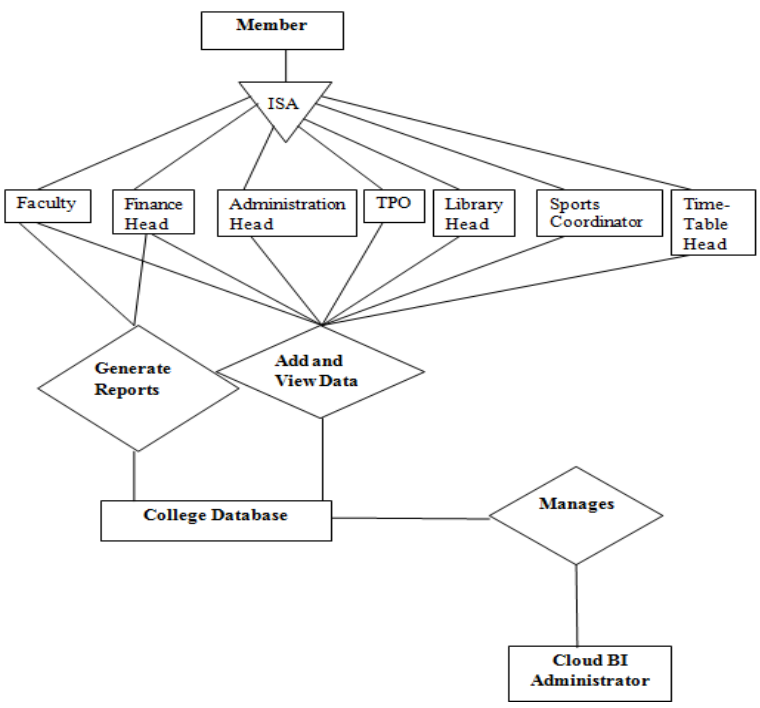

Fig 8: E-R Diagram

\subsection{Use Case Diagram:}

Each UML Diagram is designed to let developers and customers view a software system from a different perspective and in varying degree of abstraction. Use Case Diagram presents graphical overview of the functionality provided by a system in terms of actors, their goals and any dependencies between those use cases.

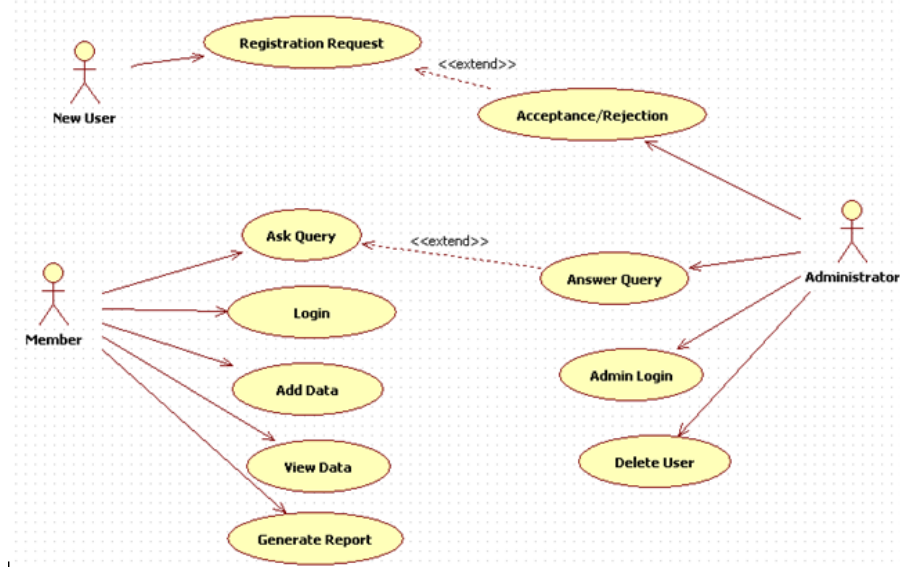

Fig 9: Use Case Diagram

\subsection{Sequence Diagram:}

Sequence Diagram allows the specification of simple runtime scenarios in a graphical manner.

\subsubsection{Sequence Diagram of New User and} Administrator

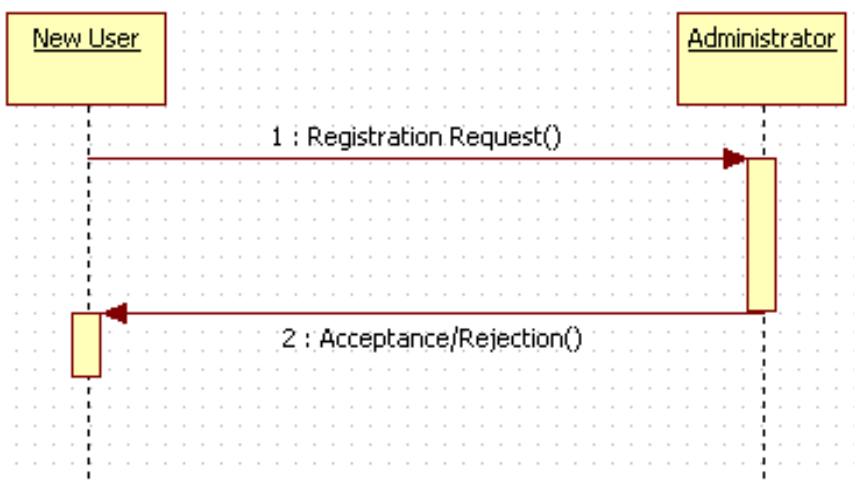

Fig 10: Sequence Diagram of New User and Administrator

6.5.2 Sequence Diagram of Member,

Administrator and Server

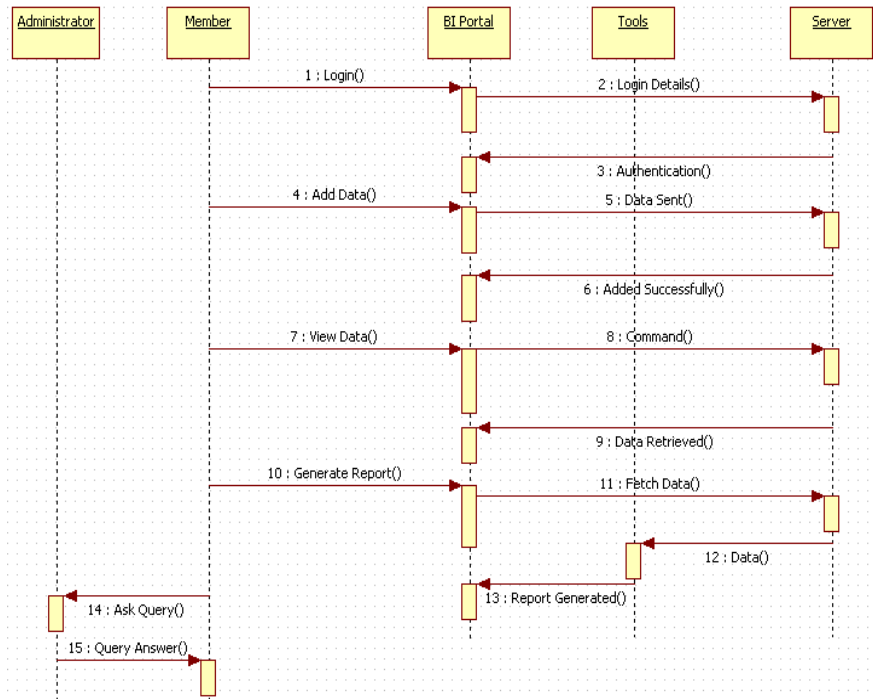

Fig 11: Sequence Diagram of Member, Administrator and Server 


\section{TOTAL COST FACTOR}

The Total Cost Factor gets lowered to a very sufficient amount when BI Cloud is used instead of BI. Organizations need not invest large amounts of money for hardware, software, licences and knowledge to put BI infrastructure up and running it. We will do cost-benefit analysis, stressing the difference between the traditional means and Cloud. The following analysis will prove that the Cloud BI Portal designed in the paper is better than the Traditional means of $\mathrm{BI}$ and thus is best suitable for small scale organizations.

We will calculate ROI(Return of Investment) indicator associated with both type of environments so as to compare the Traditional means and the Cloud .ROI is a performance measure used to evaluate the efficiency of an investment or to compare the efficiency of a number of different investments[15].

ROI $=($ Gain from Investment - Cost of Investment $) /($ Cost of Investment)

$\mathrm{TC}_{\text {Traditional BI }}=$ Total Cost in case of Traditional BI

$\mathrm{TC}_{\text {Cloud BI }}=$ Total Cost in case of Cloud BI

$\mathrm{TB}_{\text {Traditional BI }}=$ Total Benefits of Implementing Traditional BI solution

TB ${ }_{\text {Cloud }}$ BI $=$ Total Benefits of Implementing Cloud BI solution

$\mathrm{ROI}_{\text {Traditional BI }}=\mathrm{ROI}$ in case of Traditional BI solution

ROI $_{\text {Cloud BI }}=$ ROI in case of Cloud BI solution

\subsection{In Case Of Traditional BI:}

IC=Infrastructure Cost

UI=Upfront Investment (Initial Cost)

DC=Development Cost

$\mathrm{MC}=$ Maintenance Cost

$\mathrm{HC}=$ Hardware Cost

$\mathrm{SC}=$ Software Cost

$\mathrm{TC}_{\text {Traditional BI }}=\mathrm{HC}+\mathrm{IC}+\mathrm{SC}+\mathrm{DC}+\mathrm{MC}+\mathrm{UI}$

$\mathrm{ROI}_{\text {Traditional BI }}=$

( $\mathrm{TB}$ Traditional BI $\left.-\mathrm{TC}_{\text {Traditional BI }}\right) /\left(\mathrm{TC}_{\text {Traditional BI }}\right)$

\subsection{IN CASE OF CLOUD BI:}

Decreased costs are:

\section{$\Delta \mathrm{HC}=$ Decreased Hardware Cost}

$\Delta \mathrm{IC}=$ Decreased Infrastructure Cost

$\Delta \mathrm{SC}=$ Decreased Software Cost

$\Delta \mathrm{DC}=$ Decreased Development Cost

$\Delta \mathrm{MC}=$ Decreased Maintenance Cost

$\mathrm{TC}_{\text {Cloud BI }}=\Delta \mathrm{HC}+\Delta \mathrm{IC}+\Delta \mathrm{SC}+\Delta \mathrm{DC}+\Delta \mathrm{MC}+\mathrm{UI}$ (2)

$\mathrm{TB}_{\text {Cloud BI }}=$ Benefit due to Decrease in Cost + Benefit due to increase in Profit

$\mathrm{ROI}_{\text {Cloud BI }}=\left(\mathrm{TB}_{\text {Cloud BI }}-\mathrm{TC}_{\text {Cloud BI }}\right) /\left(\mathrm{TC}_{\text {Cloud BI }}\right)$

From Eqs (1) and (2) :

$$
\mathrm{TC}_{\text {Traditional BI }}>\mathrm{TC}_{\text {Cloud BI }}
$$

And

$$
\mathrm{TB}_{\text {Cloud BI }}>\mathrm{TB}_{\text {Traditional BI }}
$$

Therefore,

$$
\begin{aligned}
& \left(\mathrm{TB}_{\text {Cloud BI }}-\mathrm{TC}_{\text {Cloud BI }}\right) /\left(\mathrm{TC}_{\text {Cloud BI }}\right)> \\
& \left(\mathrm{TB}_{\text {Traditional BI}}-\mathrm{TC}_{\text {Traditional BI }}\right) /\left(\mathrm{TC}_{\text {Traditional BI }}\right)
\end{aligned}
$$

Therefore,

ROI $_{\text {Cloud BI }}>$ ROI $_{\text {Traditional BI }}$

Thus using Cloud BI is more beneficial as compared to Traditional BI as far as cost is concerned, but the risks and other factors associated with both should also be considered while making the choice. Therefore, in case of small organizations, Cloud BI will yield in more profit and increased productivity with lower investments and future costs [12], [13].

\section{CONCLUSIONS}

Cloud $\mathrm{BI}$ is set to change the BI Landscape resulting in much better adoption of BI systems and new options. We cannot ignore the cloud computing trends while development of Business Intelligence field. Our proposed model represents a new environment atmosphere for the business intelligence that help in shortening BI implementation difficulties and reduction of cost for BI programs. Business Intelligence in the cloud enhances the efficiency and productivity of business intelligence and increase the performance of BI software, thus providing small scale organizations a better option. Cloud Offerings capture more of the mid-size market because this market is more prone to loss caused by unpredictable loadvolumes, high upfront investment and longer duration for provisioning. A completely virtualized BI infrastructure that is composed as a mashup of internet services is surely rather long term vision than midterm reality - but it still needs to be watched out for. 


\section{ACKNOWLEDGMENTS}

I express my sincere and deep gratitude to my guide Mr.Prabhdeep Singh, Assistant Professor, Computer Science \& Engineering Department, Punjab Technical University, Punjab for the invaluable guidance, support and encouragement. He provided me all resource and guidance throughout work.

I am heartfelt thankful to Mr.Rajdeep Singh, Head of Computer Science \& Engineering Department, Punjab Technical University, Punjab, for providing us adequate environment, facility for carrying out work.

\section{REFERENCES}

[1] J. Ranjan, "Business intelligence: concepts, components, Techniques and benefits", Journal of Theoretical and Applied Information Technology, Volume 19,No 1, pp16,2009 .

[2] "Cloud Computing: Risks, Benefits, and Mission Enhancement for the Intelligence Community", Intelligence and National Security Alliance, White Paper,March 2012.

[3] I. Foster, Y. Zhao, I. Raicu and S. Lu," Cloud Computing and Grid Computing 360-Degree Compared", Grid Computing Environments Workshop( GCE '08),pp 12-16, November 2008.

[4] M. Vouk," Cloud Computing - Issues, Research and Implementations", Journal of Computing and Information Technology ( CIT 16(4)),pp 235 - 246, 2008.

[5] R.Fitriana, Eriyatno and T. Djatna," Progress in Business Intelligence System research : A literature Review", International Journal of Basic \& Applied Sciences (IJBAS-IJENS), Vol 11, No 03.

[6] S.Ouf and M.Nasr,"The Cloud Computing: The Future of BI in the Cloud", International Journal of Computer Theory and Engineering, Vol. 3, No. 6, December 2011.

[7] A. All, "Pros and Cons of Business Intelligence in the Cloud", IT Business Edge,2009, Available:http://www.itbusinessedge.com/cm/blogs/all/p ros-and-cons-of-business-intelligence-in-thecloud/?cs $=35060$.
[8] "Business Intelligence on the Cloud: Overview and Use Cases", TCS ,White Paper.

[9] J. Bamba," Year of Cloud BI", January 24, 2012, Available: http://tdwi.org/articles/2012/01/24/2012-yearof-cloud-bi.aspx

[10] "Cloud BI Adoption: Gauging Market Demand" Available: http://www.b-eye network.com/blogs/eckerson/archives/2011/09/cloud_bi_ adopti.php

[11] T. Schadler, "Should Your Email Live In The Cloud? A Comparative Cost Analysis, Forrester Research, Inc", 2009.

[12] "Basics of Business Intelligence Systems - An executive Interview”, IBM, White Paper, June 2003.

[13] "SaaS for small manufacturers",2nd August,2012, Available: http://www.expresscomputeronline.com/features/829saas-for-small-manufacturers

[14] B.Raichura ,V.Rao , "Reduce Total Cost of Ownership, Guarantee Quality -of- Service and Achieve Business Agility",Infosys, White Paper

[15] M. Mircea and A. Andreescu, "Using Cloud Computing in Higher Education:A Strategy to Improve Agility in the Current Financial Crisis", Academy of Economic Studies, Bucharest, Romania, 15 pages,Volume2011,Available: http://www.ibimapublishing.com/journals/CIBIMA/2011 1875547/875547.html

[16] B. Chadha and M. Iyer ," BI in a Cloud: Defining the Architecture for Quick Wins", Available: http://www.infosys.com/infosyslabs/publications/infosyslabs-briefings/pages/bi-in-acloud.aspx

[17] "Steps to Implementing a Cloud Computing strategy"Available: http://www.conjungo.com/technology/cloudcomputing/steps-to-implementing-a-cloud-computingstrategy. 